\title{
Legislation gives minister more powers
}

Early released on Feb. 25, 2009

$\mathrm{T}$ The federal government has introduced new product safety legislation that will give Health Canada the power to pull unsafe products off store shelves.

Bill C-6, the Canada Consumer Product Safety Act, makes the current voluntary recall of hazardous products mandatory, and raises the potential fine for manufacturing, advertising, importing or selling unsafe products to $\$ 5$ million. However, it does not apply to food, drugs, cosmetics or natural health products.

Under the legislation, Health Canada will also have the power to double the number of product safety inspectors it employs - currently 45 - over the next 5 years, says a Health Canada spokesperson.

In 2008, Health Canada worked with manufacturers, importers and retailers to recall 244 products, includ- ing toys and jewelry containing excessive levels of lead. Some of the products, such as faulty ski bindings that caused falls and fractures, and improperly welded bicycle frames, were directly responsible for consumer injuries. Other recalls responded to potential hazards, such as parts of plush toys that could come loose and choke small children.

Under the current Hazardous Products Act, which this legislation replaces, the Minister of Health has no power to order the recall or removal of unsafe products. Health Canada had to rely on voluntarily cooperation from industry - a situation the Consumers' Association of Canada has long found unsatisfactory.

"The Minister has been working without sufficient tools for modern day," says association President Bruce Cran. "The Act is [four] decades old."
The new legislation, which has been reintroduced after dying before last fall's federal election, requires manufacturers and retailers to conduct safety tests if Health Canada requests them, and to maintain records about product origins. It also requires mandatory reporting of any safety-related risks or injuries.

Given the large number of voluntary recalls Canada has seen, including toys with lead paint or lead content, and the presence of melamine in products, "there's a never-ending list these days of possible withdrawals," says Cran.

The critical point now for Canada's new Health Minister, Leona Aglukkaq, will be enforcement, he explains. "We're just hoping that the new minister will heavily enforce [penalties for] people who cause recurring problems." - Laura Eggertson, CMAJ

CMAJ 2009. DOI:10.1503/cmaj.090239 